Special Issue: Auxin and Gravity Response in Plants

\section{Auxin transport and a graviresponse in plants: Relevance to $A B C$ proteins}

\author{
Junichi Ueda ${ }^{1 *}$, Kensuke Miyamoto ${ }^{2}$, Eiji Uheda', \\ Mariko Oka ${ }^{3}$ \\ ${ }^{1}$ Graduate School of Science, Osaka Prefecture \\ University, 1-1 Gakuen-cho, Naka-ku, Sakai, \\ Osaka 599-8531, Japan \\ ${ }^{2}$ Faculty of Liberal Arts and Sciences, Osaka \\ Prefecture University, 1-1 Gakuen-cho, Naka-ku, \\ Sakai, Osaka 599-8531, Japan \\ ${ }^{3}$ Faculty of Agriculture, Tottori University, 4-101 \\ Koyamacho-minami, Tottori 680-8553, Japan
}

\section{Abstract}

Phospho-glycoproteins (PGPs) belong to the ATP-binding cassette protein subfamily $B$ (ABCB) subgroup of the ATP-binding cassette (ABC) transporter superfamily. The involvement of $A B C B$ proteins in auxin transport is first suggested base on the results of expression levels of PGP1/ABCB1. PGPs have also been shown to mediate the cellular and long-distance transport of auxin. Interactions among PINformed and P-glycoprotein in auxin transport have been shown although PINs and PGPs characterize coordinated and independent auxin transport mechanisms. ABC (ABCB)/ $P G P$ is also suggested to have an important role in a graviresponse in plants. This review is describing auxin transport and a graviresponse in plants focused on structures and functions of ABC proteins. (02011 Jpn. Soc. Biol. Sci. Space; Article ID: 112502009

\section{Introduction}

Plant hormone, auxin, fundamentally functions as an important factor in plant growth and development connected with a unique polar movement from cell to cell. This kind of a polar movement has not been recognized in other plant hormones and named auxin polar transport. Auxin polar transport has been shown to regulate plant growth and development, and a graviresponse in plants. STS-95 space experiments made in 1998 revealed that auxin polar transport in etiolated Alaska pea epicotyls grown in space conditions was extremely reduced to ca. $50 \%$ of that in the ground control (1 G conditions) (Ueda et al., 1999; Ueda et al., 2000). Automorphosislike growth and development and reduced auxin polar

Received: November 21, 2011; Accepted: December 20, 2011

*To whom correspondence should be addressed:

Tel: +81-(0)72-254-9733; Fax.: +81-(0)72-254-9932

E-mail: ueda@b.s.osakafu-u.ac.jp transport to ca. $50 \%$ compared to control grown on $1 \mathrm{G}$ conditions have been observed in etiolated Alaska pea seedlings grown under simulated microgravity conditions on a three-dimensional clinostat (Miyamoto et al., 2005; Hoshino et al., 2006; Hoshino et al., 2007). Auxin polar transport in etiolated ageotropum pea epicotyls, one of agravitropic mutant induced by $\mathrm{X}$-ray radiation from a wild type, Pisum sativum L. cv. Weibull's Weitor (Blixt et al., 1958; Schöldéen and Burström, 1960; Jaffe et al., 1985; Takahashi and Suge, 1991; Takahashi et al., 1991), grown under $1 G$ conditions was also reduced to ca. $50 \%$ of that in a normal type of Alaska pea (Hoshino et al., 2007). In addition, the application of auxin polar transport inhibitors, 2,3,5-triiodobenzoic acid (TIBA), $\mathrm{N}$-(1naphthyl)phthalamic acid (NPA) and 9-hydroxyfluorene9-carboxylic (HFCA), to etiolated Alaska pea seedlings grown under $1 \mathrm{G}$ conditions induced an automophosis of Alaska pea seedlings, indicating that reduced auxin polar transport is not consequence but cause of automorphosis in pea seedlings observed in space conditions (Miyamoto et al., 2005; Hoshino et al., 2006; Hoshino et al., 2007). These facts also indicate that there are close relationships between auxin polar transport and a graviresponse in plants.

Auxin polar transport has been considered to be regulated by several functional proteins. Recent works in relation to molecular aspects of auxin polar transport have shown some important points in identification of proteins controlling auxin polar transport that function as influx and efflux of auxin from out of and to inside of cells, respectively. Auxin transport proteins in the presence of plasma membrane in plant cells have been grouped in three families: AUXIN RESISTANT1/LIKE AUX1 (AUX1/ LAX) as auxin uptake symporters with two protons, PINFORMED (PIN) as efflux carriers and/or facilitators, and P-GLYCOPROTEIN (MDR/PGP/ABCB) as efflux and/or conditional transporters. Phospho-glycoproteins (PGPs) belong to the ATP-binding cassette protein subfamily $B(A B C B)$ subgroup of the ATP-binding cassette (ABC) transporter superfamily.

A first class of auxin transporters is permease-like protein. The amino acid permease-like protein AUX1 has been isolated and characterized as an auxin carrier (or facilitator) located in an anti-polar side of plasma membrane catalyzing the uptake of protonated auxin, indole-3-acetice acid (IAAH), into cells (Marchant et al., 1999; Swarup et al., 2001).

A second class of auxin transporters is PIN proteins. The study on auxin efflux carriers (or facilitators) has started from the investigation of flower formation using Arabidopsis thaliana. Important new insights were obtained through molecular characterization of Arabidopsis pin-formed or pin1 mutant (Okada et al., 1991). From this study great waves of researches about auxin polar transport have come all over the world. In 1998 AtPIN1 gene has been successfully isolated using a tagging system in Arabidopsis thaliana, suggested that a product of this gene is a protein closely related to auxin polar transport (Gälweiler et al., 1998). In addition, AGR/EIR1/PIN/WAV6 (Chen and Masson, 
2005) membrane proteins have also been found in a polar side of plasma membrane and suggested to act as efflux carriers (or facilitators) of an anion form of indole3-acetic acid (IAA') to out of cells (Gälweiler et al., 1998). These facts described above indicate there is a specific system consisting with an asymmetric distribution of these proteins in plant cells to regulate auxin polar transport. The relationships between PIN proteins and a graviresponse in plants have recently been reviewed in this journal (Miyamoto et al., 2011).

Auxin polar transport is regulated by the function of some other proteins instead of PIN proteins. The PINOID gene encodes a protein-serine/threonine (Ser/Thr) kinase (Friml et al., 2004). PINOID has been shown to function as a positive regulator of auxin polar transport. In addition, PINOID is considered to involve in the fine changing of auxin polar transport during organ formation in response to local auxin concentration (Benjamins et al., 2001). The Ser/Thr protein kinase PINOIDdependent binary switch, direct phosphorylation of the hydrophilic loop of PIN proteins, is considered to control polarity of PIN proteins and to mediate changes in auxin flow to create local gradients for patterning processes (Friml et al., 2004; Grunewald and Friml, 2010). Loss of PINOID activity alters auxin transport and gravitropism without causing an obvious change in cellular polarity (Sukumar et al., 2009). The Arabidopsis GNOM gene has also been known to encode an ARF GDP/GTP exchange factor involved in embryonic axis formation and polar localization of the auxin efflux regulator PIN1 (Geldner et al., 2004). In addition, myosins are eukaryotic molecular motors moving along actin filaments and a loss-of-function mutation for a myosin of plant-specific class XI, Arabidopsis myosin XI mutant, has reported to be defective in organelle movement and auxin polar transport (Holweg and Nick, 2004). Although auxin polar transport substantially affects a graviresponse in plants as described above, detail relationships between the function of these proteins and gravistimulation in plants have not been clear yet.

A third class of auxin transporters is phosphoglycoproteins (PGPs) that belong to the ATP-binding cassette protein subfamily $B(A B C B)$, subgroup of the ATP-binding cassette ( $A B C)$ transporter superfamily. As described in detail below, recent observations have provide us the fact that Mutidrug Resistance-like gene of Arabidopsis required for auxin transport and auxinmediated development (Noh et al., 2001; Santelia et al., 2005). In addition, mdr mutants of Arabidopsis have been shown enhanced gravi- and phototropism compared to wild type as mislocalizing AtPIN1 of auxin efflux carrier (or facilitator) (Noh et al., 2003). Different from PIN proteins, the $A B C$ transporters are uniformly distributed in plasma membrane and organelle membranes (Noh et al., 2001; Wu et al., 2007; Wu et al., 2010). These facts described above together with the evidence that MDR/ABC (ABCB)/ PGP (P-glycoprotein) have been widely found in the plant kingdom (Geisler et al., 2005; Geisler and Murphy, 2006; Petrášek et al., 2006) strongly suggest that not only AGR/ EIR1/PIN/WAV6 membrane proteins but also MDR/ABC (ABCB)/PGP (P-glycoprotein) have an important role in auxin polar transport and/or response to gravistimulation in plants.

In this review, we just focus on plant MDR/ABC $(A B C B) / P G P$ proteins and describe their important role in auxin transport and for a graviresponse in plants. In addition, we describe MDR/ABC (ABCB)/ $P G P$ proteins as $A B C$ proteins. Some reviews and mini reviews in relation to auxin transport proteins including $A B C$ proteins in plants have already been published somewhere (Titapiwatanakun and Murphy, 2009; Verrier et al., 2008; Muday and DeLong, 2001; Luschnig,

Table 1 Phospho-glycoproteins, and mutants and double mutants of these proteins described in this review

\begin{tabular}{|c|c|c|}
\hline MDR/ABC (ABCB)/PGP proteins & Plant source & Function \\
\hline ABCB1 & (human) & resistance to chemotherapeutic agents \\
\hline AtABCB1 (AtPGP1) & Arabidopsis thaliana & $\begin{array}{l}\text { ATP-dependent pump, ion channel and channel regulators } \\
\text { involvement in auxin export }\end{array}$ \\
\hline$a b c b 1 a b c b 19$ & Arabidopsis thaliana & abnormal gravity-directed growth \\
\hline brachytic2/zmabcb1 & maize & involment in auxin transport \\
\hline$d w a r f 3 / s b a b c b 1$ & sorghum & involment in auxin transport \\
\hline AtABCB4 (AtPGP4) & Arabidopsis thaliana & $\begin{array}{l}\text { function in auxin import } \\
\text { function in auxin transport }\end{array}$ \\
\hline AtABCB19 (AtPGP19) & Arabidopsis thaliana & $\begin{array}{l}\text { stabilization of PIN1 localization on the plasma membrane } \\
\text { mediating auxin polar transport }\end{array}$ \\
\hline AtMDR1 & Arabidopsis thaliana & ion channels creating efficient NPA-sensitive auxin efflux \\
\hline$m d r 1, m d r 1$ pgp 1 & Arabidopsis thaliana & impaired MDR/PGP membrane proteins \\
\hline atmdr1-100/atpgp1-100 & Arabidopsis thaliana & enhanced root gravitropism \\
\hline AtMRP5 & Arabidopsis thaliana & $\begin{array}{l}\text { multidrug resistance-associate protein } \\
\text { removal of conjugated auxin into vacuole? }\end{array}$ \\
\hline
\end{tabular}


2002). The nomenclature of $A B C$ transporters seems to be complicated and controversial very much. The nomenclature of the multidrug resistance (MDR) has been still used for ABCB subgroup due to its high specificity of transport substrates. Among members of $A B C B$ subgroup, AtABCB1 (AtPGP1), AtABCB4 (AtPGP4) and AtABCB19 (AtPGP19) have been recognized as auxin transporters in Arabidopsis thaliana as described below. Therefore, original names of genes and proteins in relation to $A B C$ transporters describing in each manuscript referred here are almost used in this review as it is. MDR/ABC (ABCB)/ PGP proteins described in this review are listed in Table 1.

\section{What are $A B C$ proteins?}

The $A B C$ superfamily is a large, ubiquitous and diverse group of proteins, most of which mediate transport across biological membranes. The members of $A B C$ proteins have been found to have a large gene family in prokaryotes and eukaryotes. ABC protein superfamily is divided into several subfamilies. What is the best known member of the ABCB subgroup? That is the human $A B C B 1$ protein which has been extensively studied for its role in increased resistance to chemotherapeutic agents resulting from its overexpression in cancer cells (Luckie et al., 2003). ABC proteins in the plant kingdom have first isolated in 1992 (Dudler and Hertig, 1992). Up to now, MDR/ABC (ABCB)/PGP (P-glycoprotein) have been recognized to distribute widely in the plant kingdom with some specific functions as well as in the animal kingdom (Geisler et al., 2005; Geisler and Murphy, 2006; Martinoia et al., 2002; Petrášek et al., 2006; Sánchez-Fernández et al., 2001). In Arabidopsis thaliana, the 21 members of ABCB subgroup have been found to exhibit both distinct and overlapping expression patterns throughout all stages of plant growth and development (Blakeslee et al., 2005). The most characterized members of Arabidopsis $A B C B$ proteins are the auxin transporters of $A B C B 1$, $A B C B 4$, and $A B C B 19$. $A B C$ proteins having functions of transporters have been shown to function not only as ATP-dependent pumps, but also as ion channels and channel regulators as well (Theodoluou, 2000). MDRlike protein such as AtMDR1 could function together with ion channels to create efficient NPA-sensitive auxin efflux mechanisms (Luschnig, 2002). ABC proteins located specifically in organella which affect plant growth and development have also been reported (Kushnir et al., 2001; Zolman et al., 2001).

Structure and function of $A B C$ proteins have recently been summarized and reviewed well (Muday an Delong, 2001; Luschnig, 2002). According to the review paper, multidrug resistance is a major impediment for successful chemotherapeutic treatment, which has stimulated research on ABC proteins tremendously (Luschnig, 2002). As well as human multidrug resistance proteins (MDR) and multidrug resistance-associate proteins (MRP), most of the $A B C$ proteins have been characterized as membrane proteins that have been implicated in ATP-dependent removal of a broad range of compounds from the cytosol. Based on the facts described above, it is quite true to say that the structure of $A B C$ proteins is almost similar to that of AUX1 and PIN1 proteins. Structures of AUX1, PIN1 and AtMDR1 are shown in Fig. 1

How is possible to incorporate $A B C$ proteins into plasma membrane and/or organelle membranes? Detail mechanisms are not clear yet but there is a possible mode of action in relation to endocytosis similar to asymmetric distribution of PIN1 and PIN2 in plasma membrane (Dhonukshe et al., 2008). However, ABCB19 has been found to be regulated by the dynamic cellular trafficking mechanisms found in PIN1 in apical tissues (Titapiwatanakun et al., 2009). In addition, the function of ABCB19 seems to be stabilized PIN1 localization on the plasma membrane in discrete cellular subdomains where the expression of PIN1 and ABCB19 genes overlaps (Titapiwatanakun et al., 2009).

\section{$A B C$ proteins and auxin transport}

The involvement of $A B C B$ proteins in auxin transport is first suggested base on the results of expression levels of PGP1/ABCB1 in Arabidopsis (Sidler et al., 1998). PGPs (P-glycoprotein) have also been shown to mediate the cellular and long-distance transport of auxin (Geisler and Murphy, 2006). Among them, AtPGP1 has been reported to involve in auxin export, while AtPGP4 appears to function in auxin import (Geisler and Murphy, 2006; Titapiwatanakun and Murphy, 2009).

\section{AUX1}
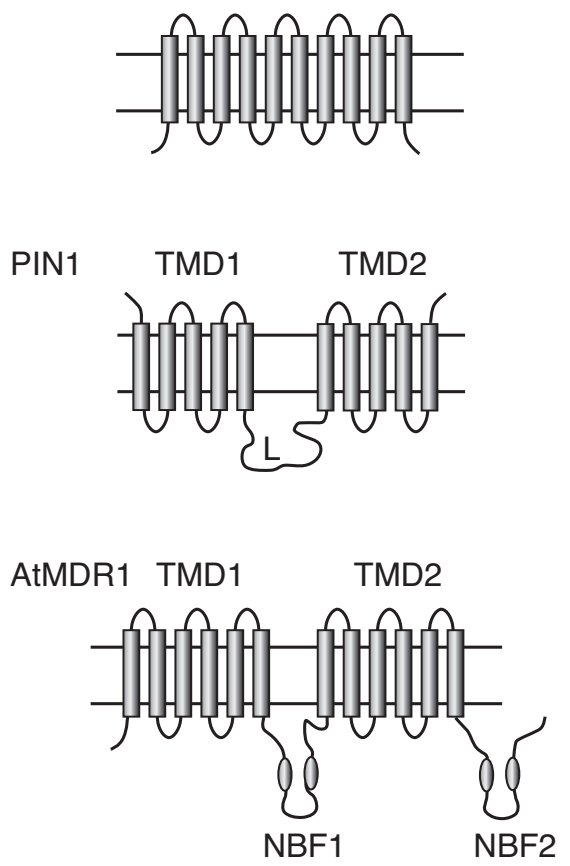

Fig. 1. Schema of AUX1, PIN1 and AtMDR1.

TMD: transmembrane domain, L: a large hydrophilic linker region, NBF: a nucleotide-binding fold. Figure is adapted from Luschnig (2002) with some modifications. 


\section{PGPs mediate direct auxin transport}

Mammalian PGP activity is regulated by protein kinase A- and C-dependent phosphorylation of the linker domain adjoining the first nucleotide-binding fold (Ambudkar et al., 2003; Castro et al., 1999), suggesting a direct link between auxin efflux and PGP phosphorylation status (Geisler and Murphy, 2006). AtPGP1 is found to be located predominantly in basal side of plasma membrane (Balška et al., 2005). This localization corresponds with both reduced auxin levels and $\mathrm{PrO}_{\mathrm{DR} 5}$ :GUS auxin reporter gene expression in atpgp1 roots (Lin and Wang, 2005). AtPGP1-meditated transport is also shown to be sensitive to auxin efflux and $A B C$ transport inhibitors (Geisler and Murphy, 2006). PGP1/ABCB1 has been subsequently shown to function coordinately with PGP19/MDR1/ ABCB19 in mediating auxin polar transport in Arabidopsis (Noh et al., 2001). Characteristic phenotypes and reduced auxin transport observed in atpgp 19 mutants strongly suggest that function of AtPGP19 is similar to that of AtPGP1. Small amounts of IAA is exported in mesophyll protoplasts isolated from atpgp19 mutants than in those from atpgp1 mutants but export of the artificial auxin, 1-NAA (1-naphthaleneacetic acid), is almost same levels as that of wild-type, suggesting that affinities of AtPGP1 and AtPGP19 to IAA are comparable but affinity to 1-NAA affinity is reduced (Geisler and Murphy, 2006). The involvement of $A B C B$ in auxin transport is also confirmed by the fact that loss-of-function of $A B C B 1$ orthologues is found to underlie the dwarf phenotypes of the agriculturallyimportant brachytic2/zmabcb1 maize and dwarf3/sbabcb1 sorghum mutants (Multani et al., 2003).

AtPGP4 is expressed predominantly during early stage in root development, suggesting that AtPGP4 is substantially involved in auxin-mediated lateral root and root hair formation and/or development. Indeed, AtPGP4 loss-of-function plants reveal enhanced lateral root initiation and root hair length (Santelia et al., 2005). These results together with the observations in yeast growth assays suggest a direct involvement of AtPGP4 in the function of auxin transport regulating lateral root and root hair development as a possible importer of auxin described above (Santelia et al., 2005; Geisler and Murphy, 2006; Titapiwatanakun and Murphy, 2009). Auxin conjugated with glucose or amino acid has been well known as storage type of auxin in vacuole. ABC transporter such as AtMRP5 has been suggested to contribute to removal of such conjugated auxin from cytoplasm into vacuole (Luschnig, 2002) although AtMRP5-GFP has been reported to localize in plasma membrane (Suh et al., 2007). AUX1, PIN1 and AtMDR1, and AtMRP5 in relation to auxin polar transport and auxin movement, respectively, are described in Fig. 2.

\section{PGP19 stabilizes PIN proteins}

Although PINs and PGPs characterize coordinated, independent auxin transport mechanisms but also function interactively in a tissue-specific manner, interactions among PIN-formed and P-glycoprotein in auxin transport in Arabidopsis have been reported (Blakeslee et al., 2007). Ectopic/overexpression of ABCB19 (ABCB19/PGP19)

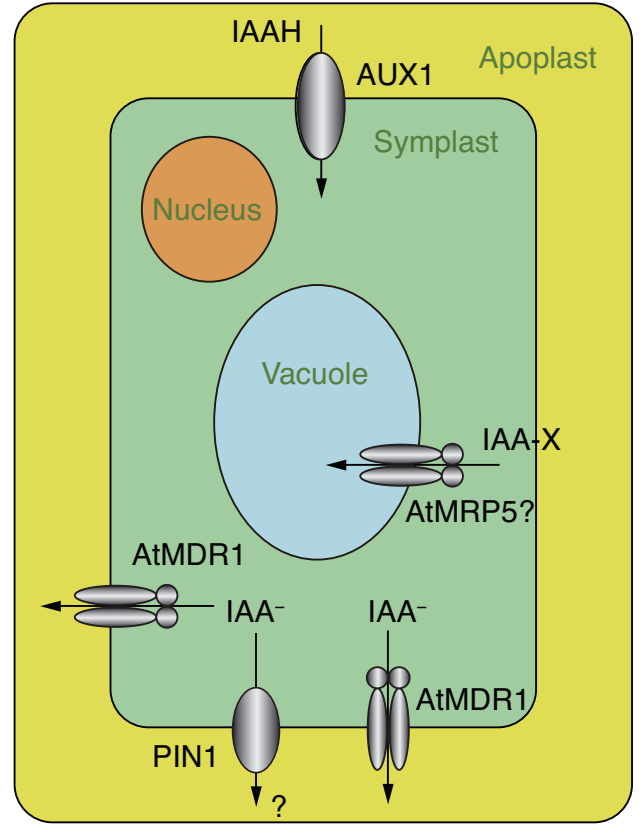

Fig. 2. AUX1, PIN1 and AtMDR1 in relation to auxin polar transport.

Figure is adapted from Luschnig (2002) with some modifications. IAAH: protonated indole-3-acetic acid, IAA : anionic form of indole-3-acetic acid, IAA-X: conjugated indole-3-acetic acid (X: glucose or amino acid), AtMRP5: ABC-transporter suggested to catalyze conjugated IAA into vacuole.

shows greatly increased endogenous levels of auxin in the hypocotyls, which reduce the sensitivity of hypocotyls growth specifically to blue light in long-term assays and red light in high-resolution, short-term assays. ABCB19 lossof-function plants partially suppressed the cry 1 hypocotyl growth phenotype in blue light. Photoreceptor mutations in cry1 and phyB both increased ABCB 19 protein levels in plasma membrane as measured by confocal microscopy (Wu et al., 2010). The evidence that PGP19 (ABCB19/ PGP19) stabilizes PIN proteins on the plasma membrane suggests that PIN-PGP interactions regulate polar auxin efflux (Blakeslee et al., 2007). PGP1 (ABCB1/PGP1) and PGP19 have eventually shown to co-localize with PIN1 in the shoot apex and with PIN1 and PIN2 in root tissues in Arabidopsis thaliana (Blakeslee et al., 2007). As described above, ABCB19/PGP19 itself has been reported to stabilize PIN1 proteins in membrane microdomains in Arabidopsis, too (Tiapiwatanakun et al., 2009).

\section{Flavonoids as inhibitors of $A B C$ proteins}

Flavonoids distributed widely in the plant kingdom have been shown to be antioxidants and kinase inhibitors (Peer et al., 2004). Flavonoids have been shown to act as negative regulators of auxin transport in vivo in Arabidopsis (Brown et al., 2001) although not confirmed to function as its modulators or regulators (Wendy and Murphy, 2007). Flavonoids have also been reported to promote asymmetric PIN shifts during gravity stimulation, thus redirecting basipetal auxin streams necessary for root bending (Santelia et al., 2008). The auxin transport inhibitor, $N$-(1-naphtyl)phtalamic acid (NPA), bound tightly 
and specifically to certain members of the group. AtMDR1 and AtPGP1 are NPA binding molecules required for the proper transport and distribution of auxin from sites of synthesis (Noh et al., 2001). Mutation of two related MDRlike genes (MDR1/ABCB1 and PGP1) substantially leads to severely reduced auxin polar transport in hypocotyls of seedlings and inflorescence stems of mature plants. The phenotype of null mdr1 and mdr1 pgp1 double mutants could be understood as consequences of impaired MDR/ PGP membrane proteins (Noh et al., 2001; Murphy et al., 2002). Flavonoids appear to compete NPA for identical sites as they reduce NPA-binding to membrane protein complexes and antagonize NPA effects on auxin accumulation (Jacobs and Rubery, 1988; Murphy et al., 2002). In addition of flavonoids, 2-[4-(diethylamino)-2hydroxybenzoyl]benzoic acid is identified as an ABCB/ $\mathrm{P}$-glycoprotein-specific inhibitor of auxin transport by chemical genomics (Kim et al., 2010).

\section{$A B C$ proteins relevance to a graviresponse in plants}

As described above, $A B C$ proteins have been shown to be fundamentally required for auxin transport and auxin-mediated development, suggesting that $A B C$ proteins are related to a graviresponse in plants. One significant finding in $m d r$ mutant of Arabidopsis has been reported in 2003. Arabidopsis $m d r$ mutants and double mutant of MDR and PGP proteins showed enhanced gravi- and phototropism compared to wild type as mislocalizing AtPIN1 of auxin efflux carrier (or facilitator) (Noh et al., 2003). The abcb1 abcb19 double mutant also shows abnormal gravity-directed growth in Arabidopsis seedlings (Wu et al., 2010), strongly suggesting that $A B C B$ is fundamentally required for a normal graviresponse in plants through its function of normal auxin polar transport systems. In addition, the atmdr1-100 and atmdr1-100/atpgp1-100 mutants have been reported to display enhanced root gravitropism (Lin and Wang, 2005). These facts strongly suggest that not only AGR/EIR1/PIN/WAV6 membrane proteins but also MDR/ABC (ABCB)/PGP (P-glycoprotein) play an important role in auxin polar transport and/or a response to gravistimulation in plants.

As far as we know, there is no evidence supported by biochemical data that PIN proteins substantially carry auxin molecules across the plasma membrane in plant cells. Coexpression of PIN and PGP transporters in HeLa cells increases substrate specificity, inhibitor sensitivity and efflux. Significant net efflux of $\left[{ }^{3} \mathrm{H}\right] \mathrm{IAA}$ is observed in HeLa cells expressing PGP1 and PGP19 but not PIN1 (Blaskeslle et al., 2007). Judging from this finding together with the fact that $A B C$ proteins are really transporter bound to plasma membrane and/or organelle membranes, there is a possibility that $A B C$ proteins do carry auxin molecules from inside to out of cells although PIN proteins are essential in auxin polar transport. Direct transport of auxin by MDR proteins or positive regulation of a PIN-type auxin efflux channel is also possible.
Further intensive studies will be required to clarify the relationships between PIN and $A B C$ proteins as well as clarification of detail functions of these proteins. Important role of $A B C$ proteins for a graviresponse in plants will also be clarified in near future.

\section{References}

Ambudkar, S.V., Kimchi-Sarfaty, C., Sauna, Z.E. and Gottesman, M.M. (2003) P-glycoprotein: from genomics to mechanism. Oncogene, 22, 7468-7485.

Balška, F., Barlow, P.W., Baskin, T., Chen, C., Feldman, L., Forde, B.G., Geisler, M., Jernstedt, J., Menzel, D., Muday, G., Murphy, A., Šamaja, J. and Volkmann, D. (2005) What is apical and what is basal in plant root development? TRENDS in Plant Sci., 10, 409-411.

Benjamins, R., Quint, A., Weijers, D., Hooykaas, P. and Offringa, R. (2001) The PINOID protein kinase regulates organ development in Arapidopsis by enhancing auxin polar transport. Development, 128, 4057-4067.

Blakeslee, J.J., Bandyopadhyay, A., Lee, O.R., Mravec, J., Titapiwatanakun, B., Sauer, M., Makam, S.N., Cheng, Y., Bouchard, R., Adamec, J., Geisler, M., Nagashima, A., Sakai, T., Martinoia, E., Friml, J., Peer, W.A. and Murphy, A.S. (2007) Interactions among PIN-FORMED and P-glycoprotein auxin transporters in Arabidopsis. Plant Cell, 19, 131-147.

Blakeslee, J.J., Peer, W.A. and Murphy, A.S. (2005) MDR/ PGP auxin transport protein and endocytic cycling. In Plant Endocytosis. (Šamaja, J., Balška, F., Menzel, D. eds.) pp. 159-176, Springer-Verlag, Berlin, Heidelberg.

Blixt, S., Ehrenberg, L. and Gelin, O. (1958) Quantitative studies of induced mutations in peas. I. Methodological investigation. Agric. Hortic. Genet., 16, 238-250.

Brown, D.E., Rashotte, A.M., Murphy, A.S., Normanly, J., Tague, B.W., Peer, W.A. Taiz, L. and Muday, G.K. (2001) Flavonoids act as negative regulators of auxin transport in vivo in Arabidopsis. Plant Physiol., 126, 524-535.

Castro, A.F., Horton, J.K., Vanoye, C.G. and Altenberg, G.A. (1999) Mechanism of inhibition of P-glycoproteinmediated drug transport by protein kinase $\mathrm{C}$ blockers. Biochem. Pharmacol., 58, 1723-1733.

Chen, R. and Masson, P.H. (2005) Auxin transport and recycling of PIN proteins in plants. In Plant Endocytosis. (Šamaja, J., Balška, F., Menzel, D. eds.) pp. 139-157, Springer-Verlag, Berlin, Heidelberg.

Dhonukshe, P., Tanaka, H., Goh, T., Ebine, K., Mähönen, A.P., Prasad, K., Blilou, I., Geldner, N., Xu, J., Uemura, T., Chory, J., Ueda, T., Nakano, A., Scheres, B. and Friml, J. (2008) Generation of cell polarity in plants links endocytosis, auxin distribution and cell fate decisions. Nature, 456, 962-966.

Dudler, R. and Hertig, C. (1992) Structure of an mdr-like gene from Arabidopsis thaliana. J. Biol. Chem., 267, 5882-5888.

Friml, J., Yang, X., Michniewicz, M., Weijers, D., Quint, A., Tietz, O., Benjamins, R., Ouwerkerk, P.B.F., Ljung, 
K., Sandberg, G., Hooykaas, P.J.J., Palme, K. and Offringa, R. (2004) A PINOID-dependent binary switch in apical-basal PIN polar targeting directs auxin efflux. Science, 306, 862-865.

Gälweiler, L., Guan, C., Müller, A., Wisman, E., Mendgen, K., Yephremov, A. and Palme, K. (1998) Regulation of polar auxin transport by AtPIN1 in Arabidopsis vascular tissue. Science, 282, 2226-2230.

Geisler, M., Blakeslee, J.J., Bouchard, R., Lee, O.R. Vincenzetti, V., Bandyopadhyay, A., Titapiwatanakun, B., Peer, W.A., Bailly, A., Richards, E.L., Ejendal, K.F.K., Smith, A.P., Baroux, C., Grossniklaus, U., Müller, A., Hrycyna, C.A., Dudler, R., Murphy, A.S. and Martinoia, E. (2005) Cellular efflux of auxin catalyzed by the Arabidopsis MDR/PGP transporter AtPGP1. Plant J., 44, 179-194.

Geisler, M. and Murphy, A.S. (2006) The ABC of auxin transport: The role of $p$-glycoproteins in plant development. FEBS Letters, 580, 1094-1102.

Geldner, N., Richter, S., Vieten, A., Marquardt, S., TorresRuiz, R.A., Mayer, Ü. and Jurgens, G. (2004) Partial loss-of-function alleles reveal a role for GNOM in auxin transport-related, post-embryonic development of Arabidopsis. Development, 131, 389-400.

Grunewald, W and Friml, J. (2010) The march of the PINs: developmental plasticity by dynamic polar targeting in plant cells. EMBO J., 29, 2700-2714.

Holweg, C. and Nick, P. (2004) Arabidopsis myosin XI mutant is defective in organelle movement and polar auxin transport. Proc. Natl. Acad. Sci., 101, 1048810493.

Hoshino, T., Miyamoto, K. and Ueda, J. (2006) Requirement of the gravity-controlled transport of auxin for a negative gravitropic response of epicotyls in the early growth stage of etiolated pea seedlings. Plant Cell Physiol., 47, 1496-1508.

Hoshino, T., Miyamoto, K. and Ueda, J. (2007) Gravitycontrolled symmetrical transport of auxin regulates a gravitropic response in the early growth stage of etiolated pea (Pisum sativum) epicotyls: studies using simulated microgravity conditions on a threedimensional clinostat and using an agravitropic mutant, ageotropum. J. Plant Res., 120, 619-628.

Jacobs, M., and Rubery, P.H. (1988) Naturally occurring auxin transport regulators. Science, 241, 346-349.

Jaffe, M.J., Takahashi, H. and Biro, R.L. (1985) A pea mutant for the study of hydrotropism in roots. Science, 230, 445-447.

Kim, J-Y., Henrichs, S., Bailly, A., Vincenzetti, V., Sovero, V., Mancuso, S., Pollen, S., Kim, D., Geisler, M. and Nam, H-G. (2010) Identification of an ABCB/P glycoprotein-specific inhibitor of auxin transport by chemical genomics. J. Biol. Chem., 285, 23309-23317.

Kushnir, S., Babiychuk, E., Storozhenko, S., Davey, M.W., Papenbrock, J., De Rycke, R., Engler, G., Stephan, U.W., Lange, H., Kispal, G., Lill, R. and Van Montagu, M. (2001) A mutation of the mitochondrial ABC transporters Sta1 leads to dwarfism and chlorosis in the Aradidopsis mutant starik. Plant Cell, 13, 89-100.
Lin, R. and Wang, H. (2005) Two homologous ATPbinding cassette transporter proteins, AtMDR1 and AtPGP1, regulate Arabidopsis photomorphogenesis and root development by mediating polar auxin transport. Plant Physiol., 138, 949-964.

Luckie, D.B., Wilterding, J.H., Krha, M., Krouse, M.E. (2003) CFTR and MDR: ABC transporters with homologous structure but divergent function. Current Genomics, 4, 225-235.

Luschnig, C. (2002) Auxin transport : ABC proteins join the club. TRENDS in Plant Sci., 7, 329-332.

Maltani, D.S., Briggs, S.P., Chamberlin, M.A., Blakeslee, J.J., Murphy, A.S. and Johal, G.S. (2003) Loss of an MDR transporter in compact stalks of maize br2 and sorghum dw3 mutants. Science, 302, 81-84.

Marchant, A., Kargul, J., May, S.T., Muller, P., Delbarre, A., Perrot-Rechenmann, C. and Bennett, M.J. (1999) AUX1 regulates root gravitropism in Arabidopsis by facilitating auxin uptake within root apical tissues. EMBO J., 18, 2066-2073.

Martinoia, E., Klein, M., Geisler, M., Bovet, L., Forestier, C., Kolukisaoglu, U., Muller-Rober, B. and Schulz, B. (2002) Multifunctionality of plant ABC transporters more than just detoxifiers. Planta, 214, 345-355.

Miyamoto, K., Hoshino, T., Yamashita, M. and Ueda J. (2005) Automorphosis of etiolated pea seedlings in space is simulated by a three-dimensional clinostat and the application of inhibitors of auxin polar transport. Physiol. Plant., 123, 467-474.

Miyamoto, K., Ueda, E., Oka, M. and Ueda, J. (2011) Auxin polar transport and automorphosis in plants. Biol. Sci. Space, 25, 57-68.

Muday, G.K. and DeLong, A. (2001) Polar auxin transport : controlling where and how much. TRENDS in Plant Sci., 6, 535-542.

Murphy, A.S., Hoogner, K.R., Peer, W.A. and Taiz, L. (2002) Identification, purification, and molecular cloning of $\mathrm{N}$-1-naphtylphthalamic acid-binding plasma membrane-associated aminopeptidase from Arabidopsis. Plant Physiol., 128, 935-950.

Noh, B., Murphy, A.S. and Spalding, E.P. (2001) Multidrug Resistance-like genes of Arabidopsis required for auxin transport and auxin-mediated development. Plant Cell, 13, 2441-2454.

Noh, B., Bandyopadhyay, A., Peer, W.A., Spalding, E.P. and Murphy, A.S. (2003) Enhanced gravi- and phototropism in plant $m d r$ mutants mislocalizing the auxin efflux protein PIN1. Nature, 423, 999-1002.

Okada, K, Ueda, J., Komaki, M.K., Bell, C.J., Shimura, Y. (1991) Requirement of the auxin polar transport system in early stages of Arabidopsis floral bud formation. Plant Cell, 3, 677-684.

Peer, W.A., Bandyopadhyay, A., Blakeslee, J.J., Makam, S.N., Chen, R.J., Masson, P.H. and Murphy, A.S. (2004) Variation in expression and protein localization of the PIN family of auxin efflux facilitator proteins in flavonoid mutants with altered auxin transport in Arabidopsis thaliana. Plant Cell, 16, 1898-1911. 
Petrášek, J., Mravec, J., Bouchard, R., Blakeslee, J.J., Abas, M., Seifertová, D., Wiśniewska, J., Tadele, Z., Kubeš, K., Čovanová, M., Dhonukshe, P., Skůpa, P., Benková, E., Perry, L., Křeček, P., Lee, O.R., Fink, G.R., Geisler, M., Murphy, A.S., Luschnig, C., Zažímalová, E. and Friml, J. (2006) PIN proteins perform a ratelimiting function in cellular auxin efflux. Science, 312, 914-918.

Sánchez-Fernández, R., Davies, E.T.G., Coleman, J.O.D. and Rea, P.A. (2001) The Arabidopsis thaliana ABC protein superfamily, a complete inventory. J. Biol. Chem., 276, 30231-30244.

Santelia, D., Henrichs, S., Vincenzetti, V., Sauer, M., Bigler, L., Klein, M., Bailly, A., Lee, Y., Friml, J., Geisler, M. and Martinoia, E. (2008) Flavonoids redirect PINmediated polar auxin fluxes during root gravitropic responses. J. Biol. Chem., 283, 31218-31226.

Santelia, D., Vincenzetti, V., Azzarello, E., Bovet, L., Fukao, Y., Duchtig, P., Mancuso, S., Martinoia, E. and Geisler, M. (2005) MDR-like ABC transporter AtPGP4 is involved in auxin-mediated lateral root and root hair development. FEBS Letters, 579, 5399-5406.

Silder, M., Hassa, P., Hasan, S., Ringli, C. and Dudler, R. (1998) Involvement of an ABC transporter in a developmental pathway regulating hypocotyls cell elongation in the light. Plant Cell, 10, 1623-1636.

Schöldéen, C. and Burström, H. (1960) Physiological studies of an ageotropic pea mutant. Physiol. Plant., 13, 831-838.

Suh, Su J., Wang, Y-F., Frelet, A., Leonhard, N., Klein, M., Forestier, C., Mueller-Roeber, B., Cho, M.H., Martinoia, E. and Schroeder, J.I. (2007) The ATP binding cassette transporter AtMRP5 modulates anion and calcium channel activities in Arabidopsis guard cells. J. Biol. Chem., 282, 1916-1924.

Sukumar, P., Edwards,K.S., Rahman,A., DeLong, A. and Muday, G.K. (2009) PINOID kinase regulates root gravitropism through modulation of PIN2-dependent basipetal auxin transport in Arabidopsis. Plant Physiol., 150, 722-735.

Swarup, R., Friml, J., Marchant, A., Ljung, K., Sandberg, G., Palme, K. and Bennett, M. (2001) Localization of the auxin permease AUX1 suggests two functionally distinct hormone transport pathways operate in the Arabidopsis root apex. Genes Dev., 15, 2648-2653.

Takahashi, H. and Suge, H. (1991) Root hydrotropism of an agravitropic pea mutant, ageotropum. Physiol. Plant., 82, 24-31.

Takahashi, H., Suge, H. and Jaffe, M.J. (1991) Agravitropic growth and its relation to the formation of the plumular hook in etiolated shoots of the pea mutant. J. Plant Physiol., 138, 216-212.

Theodoluou, F.L. (2000) Plant ABC transporters. Biochm. Biophy. Acta, 1465, 79-103.

Titapiwatanakun, B., Blakeslee, J.J., Bandyopadhyay, A., Yang, H., Mravec, J., Sauer, M., Cheng, V., Adamec, J., Nagashima, A., Geisler, M., Sakai, T., Friml, J., Peer, W.A. and Murphy, A.S. (2009) ABCB/PGP19 stabilizes
PIN1 in membrane microdomains in Arabidopsis. Plant J., 57, 27-44.

Titapiwatanakun, B., Murphy, A.S. (2009) Posttranscriptional regulation of auxin transport proteins: cellular trafficking, protein phosphorylation, protein maturation, ubiquitination, and membrane composition. J. Exp. Bot., 60, 1093-1107.

Ueda, J., Miyamoto, K., Yuda, T., Hoshino, T., Fujii, S., Mukai, C., Kamigaichi, S., Aizawa, S., Yoshizaki, I., Shimazu, T. and Fukui K. (1999) Growth and development, and auxin polar transport in higher plants under microgravity conditions in space: BRICAUX on STS-95 space experiment. J. Plant Res., 112, 487-492.

Ueda, J., Miyamoto, K., Yuda, T., Hoshino, T., Sato, K., Fujii, S., Kamigaichi, S., Izumi, R., Ishioka, N., Aizawa, S., Yoshizaki, I., Shimazu, T., Fukui, K. (2000) STS-95 space experiment for plant growth and development, and auxin polar transport. Biol. Sci. Space, 14, 47-57.

Verrier, P.J., Bird, D., Burla, B., Dassa, E, Forestier, C., Geisler, M., Klein, M., Kolukisaoglu, Ü., Lee, Y., Martinoia, E., Murphy, A., Rea, P.A., Samuels, L., Schulz, B., Spalding, E.P., Yazaki, K. and Theodoulou, T.L. (2008) Plant ABC proteins - a unified nomenclature and updated inventory. TRENDS in Plant Sci., 13, 151-159.

Wendy, A.P. and Murphy, A.S. (2007) Flavonoids and auxin transport: modulators or regulators? TRENDS in Plant Sci., 12, 556-563.

Wu, G., Cameron, J., Ljung, K. and Spalding, E.P. (2010) A role for $A B C B 19-$ midiated polar auxin transport in seedling photomorphogenesis mediated by cryptochrome 1 and pytochrome B. Plant J., 62, 179191.

Wu, G., Lewis, D.R. and Spaldin, E.P. (2007) Mutation in Arabidopsis multidrug resistance-like ANC transporters separate the roles of acropetal and basipetal auxin transport in lateral root development. Plant Cell, 19, 1826-1837.

Zolman, B.K., Silva, I.D. and Bartel, B. (2001) The Arabidopsis pxa1 mutant is defective in an ATP. binding cassette transporter-like protein required for peroxisomal fatty acid $\beta$-oxidation. Plant Physiol., 127, 1266-1278. 